\title{
El diálogo de los amantes
}

(Se apaga una canción. El triste vuelve de su ensueño y dice):

EL TRISTE

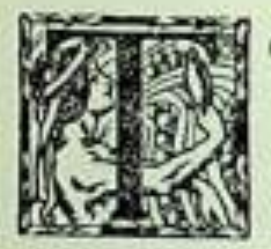

ODA la noche cantó la fuente como un pájaro.

Abri la ventana y la alcoba en penumbra se llenó de luna y de canto.

Embriagado en la música me dormí en la noche como en un regazo.

Llegó la mañana y el frío y se fueron la luna y el canto.

Se deshizo el regazo que tejieron los rayos de plata a mis sienes febriles y a mis ojos insomnes surcados de violetas ojeras.

Miro la miseria de todos los días y es amarga la vida y erizada la senda de espinas.

\section{LA ANIMADORA}

(Entra resplandeciente con el primer rayo de la mañana).

La floresta se puebla de sátiros ágiles que danzan y cantan. Es bella la vida. Agito mi tirso florido; derramo racimos vibrantes; el yermo da flores azules; las piedras revientan de un temblor de amor; la aldea sacude su gesto de abuela y, como una niña jubilosa, ríe. La vieja casona colonial desnuda de enredadera se viste y, como un velo de novia, florece. Carabelas de cristal navegan en el aire, mar primaveral y fragante. Es bella la vida. Dancemos. Cantemos. Amemos. 


\section{CORO}

Dancemos. Cantemos. Amemos.

Al cielo los brazos alcemos:

los sones alados cantemos:

cantando y amando, dancemos.

Dancemos. Cantemos. Amemos.

Cantemos la gloria del vino:

beber es un rito divino:

libar es un culto pagano:

cantemos el vino divino y humano.

El vino divino y humano cantemos; con nuestras manos el jugo estrujemos, a nuestros labios su esencia llevemos y, al embriagarnos la danza, cantemos. Amemos. Cantemos. Dancemos.

Es nuestra sangre como un vino ardiente. el vino es la sangre inmortal de la viña: nos mire el sol al nacer en Oriente ebrios del aire que da la campiña.

Ebrios de un vino de amor y locura que al embriagarnos nos haga danzar y que al danzar en la atmósfera pura aires de ensueño nos haga cantar.

\section{EL TRISTE}

Es dura la vida: en la entraña sangrante nos clava la garra y nos deja una herida que nunca se cierra. En la dorada lejanía veo perderse los árboles que parecen llamarme para colgar en sus cimas floridas mi calavera de ahorcado, siniestra. La vida es madrastra: es dura y amarga.

\section{LA ANIMADORA}

Mi tirso florece y es mi báculo, mi cetro, mi espada. 


\section{EL TRISTE}

Mi angustia se agranda y es toda mi vida.

\section{LA ANIMADORA}

Es la ruta del sol mi camino y la luna me teje con sus copos de nieve la túnica albísima con la que cruzo el silencio nocturno.

\section{EL TRISTE}

Rumores de guerra conmueven la tierra; dias de llanto, de espanto y quebranto, oscuras miserias y torvas lacerias. como un humo gris me van ahogando.

\section{LA ANIMADORA}

Bebí mi vino y mi miel de locura: ciega erraré por la vasta llanura. me perderé por el monte, en la altura, ebria en mi vino de amor y locura.

EL TRISTE

Por la herida aleve que el amor me hiciera se fué de mi espíritu la azul primavera. En una otoñada vesperal y lenta. como un ala, sin que nadie la sienta, se va disolviendo mi vida violenta: cae como alada hoja amarillenta. Ella fué rebelde, viril, turbulenta y ahora se pierde como una hoja lenta.

\section{LA ANIMADORA}

Mis ojos viven del cielo extasiados y de mirar primavera en los prados. Hoy los senderos están encantados.

\section{EL TRISTE}

El pájaro que cantó en la noche murió en la mañana.

\section{LA ANIMADORA}

El árbol vibra como una campana. 
EL TRISTE

Es silenciosa e inmóvil la planta.

\section{LA ANIMADORA}

Al que sabe oir el árbol le canta.

EL TRISTE

Toda alegria es efímera y breve.

\section{LA ANIMADORA}

Un río canta al fundirse la nieve.

EL TRISTE

El río a lo lejos cantando se pierde.

LA ANIMADORA

Florece a su orilla la floresta verde.

\section{EL TRISTE}

Dero la floresta se mustia y fenece.

\section{LA ANIMADORA}

Cuando fenece de nuevo florece.

$$
\text { EL TRISTE }
$$

Tu voz musical morirá algún día.

\section{LA ANIMADORA}

Le dará el cristal a otra melodía.

$$
\text { EL TRISTE }
$$

Se secará el tirso de tu viña eximia. 


\section{LA ANIMADORA}

Dará su sangre en la ardiente vendimia.

EL TRISTE

Mirar el mundo es llenarse de horror.

\section{LA ANIMADORA}

Florecerán fus entrañas de amor.

\section{EL TRISTE}

Pero, después del amor, moriremos.

\section{LA ANIMADORA}

Pero, después de morir, volveremos.

\section{EL TRISTE}

A llenarnos los ojos de llanto.

\section{LA ANIMADORA}

A estrujar el panal del encanto.

\section{EL TRISTE}

¿Y sobre la ceniza ardiente de mi amor como en el tiempo antiguo podrá cuajar la flor?

\section{LA ANIMADORA}

Como una clara albada de cristal musical al cantar de la fuente florecerá el rosal.

\section{EL TRISTE}

Como cuna de niño se llenará la fuente de rosas que la brisa al besarlas reviente. 


\section{LA ANIMADORA}

Un ataúd de Ofelia es la fuente florida:

el perfume le canta una canción de vida.

EL TRISTE

Viene una nueva brisa y ese perfume muere.

\section{LA ANIMADORA}

Pero despierta llena de color cuando quiere y en flores cristalinas de su divina forma.

EL TRISTE

El hastio en la vida es la suprema norma.

\section{LA ANIMADORA}

Es la suprema norma en la vida el hastio para el que no ha mirado el sol matutinal, para el que no ha plantado su huerto junto al río que es un camino azul, sereno y musical.

Para el que no ha regado con su sangre más pura el encendido y diáfano corazón del rosal; para el que se ha perdido entre la selva oscura sin hallar el sendero del laurel inmortal.

Hay que tener los ojos serenos; en la altura una flor luminosa nos viste de cristal, nos sutiliza la divina envoltura y mueve nuestros músculos un aire musical.

De los padres primeros somos una escultura antes de conocer la Fruta original; toda la tierra siente una santa dulzura y canta por la voz fresca del manantial.

EL TRISTE

Estéril es la tierra como un seno estrujado. 


\section{LA ANIMADORA}

El corazón de la tierra es sagrado.

\section{EL TRISTE}

El sol ha de secar el canto de la fuente.

\section{LA ANIMADORA}

El cielo ha de mirarse en ella eternamente.

$$
\text { EL TRISTE }
$$

Los elementos deben un día terminar.

\section{LA ANIMADORA}

Su sinfonía es eterna como el mar.

\section{EL TRISTE}

El mar, en la corriente inminente y fatal, naufragará en todo aliento elemental.

\section{LA ANIMADORA}

Muerta la aurora de hoy vendrá la de mañana a despertar al mundo con sus dedos de grana.

\section{EL TRISTE}

Es amarga la vida y triste el pensamiento.

\section{LA ANIMADORA}

Dara el que sabe ver es un florecimiento y pensar es vivir en un encantamiento.

\section{EL TRISTE}

Leves hojas de ofoño. les desparrama el viento. 


\section{LA ANIMADORA}

La vida, como un hada, fecunda las auroras.

\section{EL TRISTE}

Como una bruja estéril va abortando las horas.

\section{LA ANIMADORA}

Con gracia inmaterial van bordando su danza las horas melodiosas y el ritmo aéreo alcanza a sumarse a la música de luz de las estrellas...

EL TRISTE

Vana inutilidad la de las cosas bellas.

\section{LA ANIMADORA}

Santa inutilidad, como un poeta canta con una voz de seda que acaricia y encanta.

\section{EL TRISTE}

La efernidad perdura, to efimero resbala...

\section{LA ANIMADORA}

Es eterno el femblor de la fuente y el ala.

EL TRISTE

La forma se deshace y la esencia perdura.

\section{LA ANIMADORA}

Es la esencia del rostro su plenitud más pura y la línea cincela su eterna perfección.

\section{EL TRISTE}

Dura esa linea lo que dura una canción. 


\section{LA ANIMADORA}

Una canción no muere: cuando se está apagando para $t i$, vive en otros vibrando y resonando...

EL TRISTE

Amarga roca estéril es la filosolía.

\section{LA ANIMADORA}

En sus cumbres florece la más alta poesía.

Resuena a lo lejos una canción de primavera. Canta el coro. La animadora habla al oído del triste. Lo va llenando de flores. Un grupo de efebos y virgenes, envuelto en luz rosada, lo rodea danzando un aire primaveral. Se retiran cantando el coro. El triste. transfigurado por la exaltación, dice:

EL TRISTE

Rincón de los convalecientes

y los adolescentes

florecientes;

sol matinal,

primaveral,

divino sol inmortal.

por tu contacto celestial

la sangre hierve y se alborota.

como un torrente irrumpe y brota

y va cantando y floreciendo

$y$ esparciendo

sus claras rosas melodiosas

sobre el júbilo de las cosas

de la tierra virgen que espera

el beso de la primavera!

Canta el coro. El triste, más y más exaltado, a la animadora: 
Que sea nuestro báculo de errantes peregrinos el tirso que florece en tus brazos divinos!

La animadora le ha pasado el tirso. Y dice:

\section{LA ANIMADORA}

Los sátiros, en la gracia de un rito pagano y sonoro, hacen vibrar sus divinos cuerpos ágiles como una religiosa exhalación de la montaña. Van coronados de pámpanos y beben el musical jugo de la tierra, un licor de locura y amor que al dar a sus cuerpos un temblor más liviano. da alas a las fervorosas palabras que brotan de sus labios. Ellos beben y cantan y danzan y rien. Dancemos. Cantemos. Amemos.

Canla el coro

\section{EL TRISTE}

Con exaltación.

Loca vendimia de la carne frágil, te siento perfumar la primavera con tu pámpano azul y tembloroso, con tu racimo rojo y palpitante.

En la copa de oro del pecado quiero beber hasta las heces como si bebiera en la palma del camino la miel que se destila en sus heridas: así un ave del cielo se embriagara en un bosque de sándalos benditos.

Quiero beber en tu oro perfumado, cáliz primaveral.

Me estremezco como una llamarada al sentir en la brasa de mis labios, copa de fiebre de un licor de fuego. la púrpura quemante de sus labios!

Bajo la vid de la locura nueva, vestida en claridad, la primavera florece en plena desnudez perfecta. Las serpientes de leche de sus brazos quiero sentirlas en mi barro humano, el tornasol de su mirada cálida me envuelva como un astro hasta la tarde en que caigan. como hojas del camino, mis pámpanos, racimos y semillas...

\section{LA ANIMADORA}

Hay una mariposa que se posa en la rosa:

una rosa que vuela es cada mariposa:

entreguemos al viento el alma jubilosa

como un vilano blanco que en el cielo se posa

y como estrella alumbra la tierra fervorosa... 


\section{EL TRISTE}

Animadora mía, canternos, dancemos, amemos.

Canta el coro.

EL TRISTE

Con locura.

La fierra divina y florida

revienta y estalla de vida

como una milagrosa flor:

si alzamos la venda a la herida

florece una estrella encendida

que a todos nos llena de amor.

La danza es un canto que encanta

que el tedio deshace y espanta

y al cuerpo le da ingravidez:

la savia es un himno en la planta

y el ritmo en la clara garganta

tiene un vuelo de santa avidez.

Dancemos. Cantemos. Amemos.

Los brazos en ágiles remos

abran surcos al mar de cristal.

Amemos, cantemos, dancemos.

por toda la vida crucemos

henchidos de un ansia inmortal.

Canta el coro. Suena a lo lejos una música de primavera.

ROBERTO MEZA FUENTES. 